Pakistan Journal of Humanities and Social Sciences

April - June 2019, Volume 7, No. 2, Pages 203 - 217

\title{
Oil Prices Dynamics and the State of Energy Crisis in Pakistan
}

\author{
Jibran Hussain ${ }^{1}$, Sallahuddin Hassan ${ }^{2}$ \\ ${ }^{1} \mathrm{Ph} . \mathrm{D}$. Scholar, School of Economics, Finance and Banking, Universiti Utara Malaysia \\ ${ }^{2}$ Professor, School of Economics, Finance and Banking, Universiti Utara Malaysia \\ Email: jibranhr@gmail.com
}

\begin{abstract}
The dependence on non-renewable energy sources is the key factor controlling international oil prices, geoeconomics, geopolitical and geostrategic relations, business and macroeconomic dynamics. The developing economies remain volatile to oil price due to their heavy reliance on non-renewable energy sources and their low capability to maintain stable energy stock, such as Pakistan. The existing weak, unstable energy system has not been able to devour the frequent blows of oil price volatilize and shocks over the years and have been provoking energy crisis in the country. The application of vector error correction mechanism shows a statistically significant positive impact of oil prices on the energy crisis in the long run as well as in the short run.
\end{abstract}

Keywords: Energy Crisis, Oil Price Shocks, Electricity Crisis, Circular Debt

\section{Introduction}

The oil embargo of the seventies, the political crisis of Iran revolution (1979) at the starting of Iran-Iraq war, the oil glut of the eighties, the gulf war of the nineties, the volatilities of 2007 and 2011 pulled series of oil price shocks all over the globe in general and upon the western economies in particular. Despite the global transformation move towards the development of renewable energy as an alternate energy resource, the age of oil is not over yet. The modern world still relies heavily on non-renewable sources of energy, with almost 81 percent of the world's gross energy consumption (World Bank, 2015). The OPEC is enjoying hegemonic control over oil price in totality to keep the petroleum prices inflated at the international markets. The collective impact of Iran-Iraq war and Kuwait invasion in 1990 brought another energy shock to the western and on to the USA, and pushed into another recession. The bluff of Enron Corporation in 2000 with the electricity prices invited power shocks and energy crises to the state of California, USA (Federal Energy Regulatory Commision , 2003). The region of North America was under a severe shortage of energy 
supplies, especially during the year 2000 to 2008 it wsa seriously affected by the gas crisis. The rapidly growing Argentina in post-recession of 2002, could not meet the required energy supplies due to the damage caused by energy crisis to the economic infrastructure. The beginning of the millennium remained crucial in terms of energy supplies for many countries around the globe, especially the first decade; Zimbabwe, North Korea, Burma, South Africa, China, and Pakistan, remained victim of severe energy crisis to date (Kiani, 2006). The deprivation of contemporary resources of energy, services and supplies for billions in this world, restrained the process of economic growth but also exacerbates the energy crisis (Bazilian \& Yumkella, 2015).

\section{Literature Review}

The major and important economic variables such as unemployment, general prices, income and input prices are immediate targets of oil price fluctuations (Hamilton, 1983). The input and output prices host the immediate fallout of oil price dynamics, which eventually translates into the inflation, decreasing real incomes, employment and the economy slips towards imbalance and recessions (Hamilton, 2000). Also noted by Parker (2017) who believed the global oil prices are inflated because of the hikes in international energy prices as well the food prices. While working with the data of more than 200 countries and their consumer price index, he found that the dynamics of energy prices fuelled by oil price fluctuations and shocks is a major contributor and factor of global food price fluctuations. Hence, oil price shocks not only create food price fluctuations but also responsible for inflationary pressure in major economies of the world. A significant character of exogenous factors is that they lead to internal crisis and the crisis eventually translates as policy transformation, reformation, and restructuring (Grossman, 2014). By its nature, the international oil dynamics reshaped the international geopolitical and geo-economic dynamics and relationships globally, with the energy shock 1973 and the Iranian domestic religious takeover of 1979 have been responsible for creating a crisis, recessions and changing geo-political dynamics (Hamilton, 2003).

Economic progress, growth, and stability of Pakistan are highly dependent on external factors (McCartney, 2011). Reliance on imported oil is one of such reasons that the production of power in Pakistan is very high. Due to which financial standing and sustainability of energy institutions are at risk. This extra dependency on imported energy effects energy crisis in several ways, the emergence of the energy crisis is due to the supply-demand gap, which is an outcome of bad governance decisions is one of them (Malik, 2012). Primarily through two broad avenues in case of oil-dependent economies the economic infrastructure remains a victim of oil price 
volatilities. As the upsurge in energy price leads to surge input and out prices, moreover, it decreases real income and deprives masses of energy supplies. On the other hand, inflated energy prices reduce state capacity to produce the existing level of energy supplies without sacrificing the additional cost, which eventually reduces the energy used per capita, and increases the energy crisis (Alahdad, 2012).

Impact of international oil price dynamics falls upon the domestic general price levels and inflation in Pakistan directly. Haider et al. (2014) believed that the inflation rate in Pakistan is predominantly drive by international energy market dynamics. As, the country has a very meek indigenous production capacity and has a massive reliance on oil imports, which accounts for almost 80 percent of its oil requirements. This result implies that general price level is heavily depended on oil price dynamics and any volatility at international oil prices would immediate translates on to the domestic energy sector and spreads throughout the economy (Valasai et al., 2017). Acceded by Malik et al. (2017) that the negative and statistically significant impact of oil prices on the growth process, inflation, and interest rates in long-run. Quite the reverse, the impact of oil prices on the economy is considered to have in the short run more drastic than in the long run (Rafay \& Farid, 2015). Despite the noteworthy role of oil prices on inflation, interest rates, and economy, Jamali et al. (2011) believed that the impact of oil prices could be mitigated if alternative energy sources are explored, supported by Rafique and Rehman (2017) for sustainable energy supplies and a solution to the ongoing energy crisis. Increasing oil prices put the direct burden on the government in the form of expensive subsidies, energy mix gets a more and more irrational and expensive burden on the exchequer, whereas the increasing circular debt is yet another serious threat to national energy security and sustainability (Valasai et al., 2017). Wherein, the shortage of oil and expensive cost of production due to international oil prices is the root cause of circular debt in Pakistan. The existing energy policy is a base of the prevailing energy crisis and a security and economic threat to the future of the country (Zameer \& Wang, 2017).

Similar, concerns are portrayed by Mirjat et al. (2017) that poor planning in the energy sector led by weak political institutions left the whole sector naked to international energy dynamics which is the leading reason of this on-going energy crisis in the country. The authors' believed that the instability of the energy sector to oil prices is because of incapable energy institutes, and the persistence of current energy policies are not only going to worsen existing energy crisis situation but are a potential threat to national security. Such concerns are already stated by Popescua (2015), and warned countries with a low level of energy usage (India, Pakistan) would 
suffer from global energy security dynamics, the plausible impact would be that citizens of poor (in terms of per capita energy use) countries would be using less energy than today, if they are failed to resolve their energy security issues well in time. Similar results were rested in the form of national and energy security threat by Shahir and Quershi (2007) in case of Pakistan, where they warned that the depleting resources of energy would result into socioeconomic crisis.

\section{Theoretical Framework}

Theoretical framework rendered in this paper is architecture on the foundations of a comprehensive theory of oil prices (Hamilton, 1983, 1996). The framework consisting oil price volatility linking directly with the energy crisis. Whereas the impact of oil prices integrated as interactions with different factors of energy such as circular debt, energy mix, and transmission, dispatch losses are shown. The controlled variables include political instability, population, and economic growth.

\section{Figure 1: Theoretical Framework}

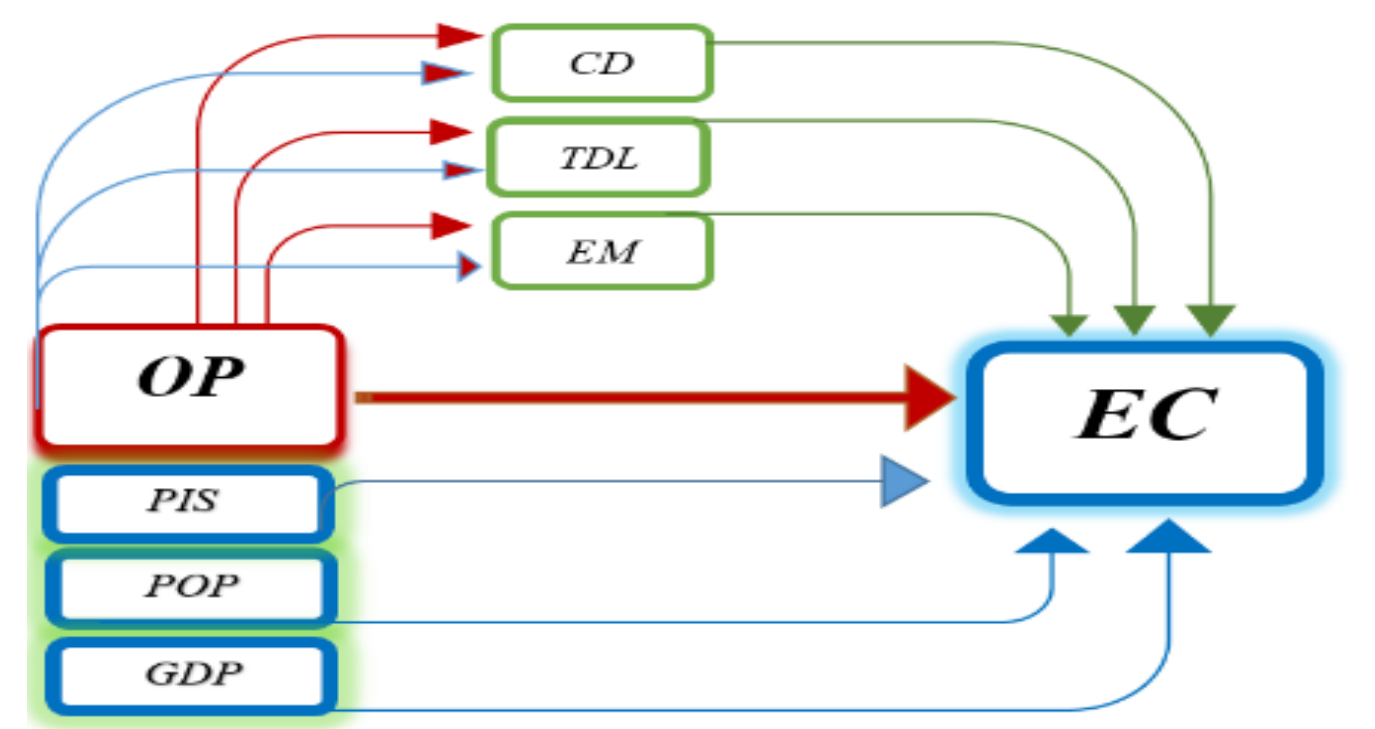

Source: The authors

\section{Methodology}

This section in extension to the previous section thus develops an econometric understanding of ongoing research. Section III attempts to incorporate the most appropriate and well-suited research methodology in the form of a theoretical framework. Section IV entails the application of stationarity method for unit root analysis. Moreover, cointegration tests are employed for long run relationships. The model in the section utilized and the respective specifications of Vector Error Correction Method (VECM), with the objective to have a detailed 
impact of oil prices on energy crisis along with interactions of oil prices. Section 4 enlists all sources of data required and used in this study. Subsection B incorporates the method of analysis in accordance with the proposed research methodology.

\section{A. Oil Price and Energy Crisis Model}

Technically, VECM is a suitable technique to see if the variables selected are cointegrating in the long run, that is of their vectors have cointegration, and has a tendency to address the deviations from the equilibrium (Johansen, 1991). In a system of variables, there is the possibility of many linearly independent cointegrating vectors, where their vector combinations are also cointegrated (Davidson et al., 1978).

Moreover, the conceptual propagation and application of cointegration are in debt to the works of Granger (1981), Salmon (1982) along with Engle and Granger (1987). The VECM model requires to allow for the cointegrating relationship between the nonstationary variables. Therefore, to ensure the best technique that takes into account the requirements of time series data. A general VECM model has presented herein as Equation (1).

$$
\Delta y_{t}=\alpha_{0}+\sum_{i=1}^{n} \beta_{i} \Delta y_{t-i}+\sum_{i=0}^{n} \delta_{i} \Delta x_{t-i}+\lambda z_{t-1}+\varepsilon_{t}
$$

where $\alpha_{0}$ is intercept, $\Delta$ represents a change, $\beta_{i}$ is the coefficient of lag dependent and $\delta_{i}$ represents the coefficient of explanatory variables, $i=1,2,3, \ldots, n$. The $\lambda$ is a coefficient of $E C T$ and $\varepsilon_{t}$ is error term.

To inquire historical behaviour of oil price volatilities on energy crisis on economic development and different aspects and phases of growth, it is mandatory to have accurate data and information on different energy components and oil prices, in our case from 1971 to 2016. This paper is focused on different sources of energy and energy commodities that collectively contribute to the provision of energy supplies and services. These include circular debt, energy mix, transmission, and dispatch losses. The study relies upon the secondary, time-series data, for 1971 to 2016 of Pakistan economy. Through an extensive library survey and research, various data sources are reached out to collect the desired data. These data sources including; ICRG for the collection of data on political stability and its various components. Whereas, Pakistan Bureau of Statistic, Ministry of Energy Pakistan and Pakistan Economic Surveys are reached to collect data on energy supply and demand. Whereas, the collection of data for $C D$, $T D L$, and $E M$ is collected from archives of government policy papers of the Ministry of Finance and Ministry of Energy, Government of Pakistan, various energy yearbooks. Wherein, the data on development indicators are collected from World Bank Development Indicators (MDIs).

\section{B. Method of Analysis}


Augmented Dicky-Fuller (ADF) method is an elaborative and efficient econometric extension to DF test discussed in preceded paragraphs. One of the most effective, powerful, advanced and consistent units root test is ADF, well established as the ADF test in the popular literature. The ADF distinguished from DF in several technical ways, such as ADF removes all structural effects such as issues of autocorrelation while adding extra lagged terms of a dependent in the time series, hence can be used with serial correlation. The Cointegration is an econometric technique that explains the relationships and equilibriums between the underlined economic variables of time series that converges over time in the long run. If ordinary least square regression is estimated where the residuals are non-stationary along with yields spurious result. To overcome this issue, the unit root analysis is mandatory. If both sets of data are I(1) (non-stationary), then if the regression produces an $\mathrm{I}(0)$ error term, the equation is said to be cointegrated (Engle \& Granger,1987).

When it comes to having time series modelling, where the information of long-run variables is inevitable to intact, the cointegration test is the best choice. Therefore, cointegration facilitates and provides a strong economic and statistical basis for the empirical error correction modelling. Hence, a test for cointegration remains fundamental and mandatory condition to establish the provision and presence of long-run relationship. Therefore, this paper opts for Johansen's cointegration test proposed by Johansen $(1988,1991)$ maximum eigenvalue and trace statistics to investigate relationship between $O P$ and $E C$ in the long run, while his methodology takes pivotal point from testing Vector Autoregressive (VAR). In general notations for any set of time series variables, $y_{t}=\left(y_{1 t}, y_{2 t}, \ldots, y_{n t}\right)$, ARDL $p$ mothe del can be articulated in Equation (2);

$$
y_{t}=\alpha_{1}+\varphi_{2} y_{t-1}+\ldots . .+\varphi_{p} y_{t-p}+\varepsilon_{t}
$$

where, $\varphi_{i}$ are $(\mathrm{n} * \mathrm{n})$ coefficient matrices and $\varepsilon \sim i i d . N\left(0, \sigma^{2}\right)$ is an unobservable iid, zero mean error term $\varepsilon_{t}$ is known as an $n^{*} 1$ vector of innovations. Equation (2) may be rewritten as in Equation (3);

$$
\Delta y_{t}=\alpha_{1}+\lambda y_{t-1}+\sum_{i=1}^{p-1} \mu_{i} \Delta y_{t-i}+\varepsilon_{t}
$$

where $\lambda=\sum_{i=1}^{p} A_{i}-\mathrm{I}$ and $\mu=\sum_{j=i+1}^{p} A_{j}, \lambda$ shows reduced rank $r<n$, therefore, there exisits $n * r$ matrices $\alpha$ and $\beta$ having a stationary rank with $r$, that is $\lambda=\alpha \beta^{\prime}$ and $\beta^{\prime} y_{t}$. Whereas, $r$ shows total number of relationships having cointegration, element $\alpha$ is the parameter of adjustment in VECM, whereas, each of the column of $\beta$ is considered as the vector 
of cointegration. Johansen proposed two tests known as likelihood tests, such as maximum eigenvalue test and trace test, the same are exhibited in Equation (4) and (5);

$$
\begin{gathered}
J_{\text {Max }}=-T \ln \left(1-\hat{\lambda}_{r+1}\right) \\
J_{\text {trace }}=-T \sum_{i=r+1}^{n} \ln \left(1-\hat{\lambda}_{i}\right)
\end{gathered}
$$

where, $T$ is the sample size and $\hat{\lambda}_{i}$ is the largest correlation. The maximum eigenvalues are a set of values of the parameter for which a differential equation has a non-zero solution (an eigenfunction) under a given condition.

\section{Long Run Relationship}

The long run relationship is imposed through the significance or otherwise of the ' $t$ ' test of the lagged error-correction term(s). Non-significance or elimination of any of the lagged error-correction terms affects the implied long-run relationship (Thomas, 1993). The long-run VECM model is presented in Equation (6);

$$
\begin{gathered}
\Delta E C_{t}=\alpha_{0}+\beta_{1} \Delta E C_{t-1}+\zeta_{1} \Delta O P S_{t}+\zeta_{2} \Delta P I S_{t}++\zeta_{3} \Delta C D_{t}+\zeta_{4} \Delta E M_{t}+\zeta_{5} \Delta T D L_{t}+ \\
\zeta_{6} \Delta(O P S * P O P)_{t}+\zeta_{7} \Delta(O P S * E M)_{t}+\zeta_{8} \Delta(O P S * C D)_{t}+\zeta_{9} \Delta(O P S * T D L)_{t}+ \\
\zeta_{10} \Delta G D P_{t}+\zeta_{11} \Delta P O P_{t}+\varepsilon_{t}
\end{gathered}
$$

where $\alpha_{0}$ is intercept $\beta_{1}$ is the coefficient of the lag of the dependent variable, $t=$ $1,2, \ldots, T, \varepsilon_{t}$ is error term. $\zeta_{i}(i=1,2, \ldots, 5)$ are coefficients of explanatory variables $\zeta_{i}(i=6,7, \ldots, 9)$ represents coefficients of interaction terms and $\zeta_{i}(i=10,11)$ represents coefficients of controlled explanatory variables of the long run.

\section{Short Run Relationship}

The economic factors have a tendency to persistently move upward and downward, if such a stochastic behaviour is motivated in a set of linear stationary combination of integrated variables jointly, hence considered as cointegrated relationships (equilibrium relationships). These relationships could be improvised through reparametrizing the VAR model into VECM. Therefore, for the short and long run, this section focuses on the reduced form of the VECM model. Hence, the VECM specification is propagated in Equation (7);

$$
\begin{aligned}
\Delta E C_{t} & =\alpha_{0}+\lambda E C T_{t-1}+\sum_{i=1}^{n} \beta_{i} \Delta E C_{t-i}+\sum_{i=0}^{n} \delta_{1} \Delta O P S_{t-i}+\sum_{i=0}^{n} \delta_{2} \Delta P I S_{t-i}+ \\
& \sum_{i=0}^{n} \delta_{3} \Delta P O P_{t-i}+\sum_{i=0}^{n} \delta_{4} \Delta G D P_{t-i}+\sum_{i=0}^{n} \delta_{5} \Delta C D_{t-i}+\sum_{i=0}^{n} \delta_{6} \Delta E M_{t-i}+ \\
& \sum_{i=0}^{n} \delta_{7} \Delta T D L_{t-i}+\sum_{i=0}^{n} \delta_{8} \Delta(O P S * P O P)_{t-i}+\sum_{i=0}^{n} \delta_{9} \Delta(O P S * E M)_{t-i}+ \\
& \sum_{i=0}^{n} \delta_{10} \Delta(O P S * C D)_{t-i}+\sum_{i=0}^{n} \delta_{11} \Delta(O P S * T D L)_{t-i}+\varepsilon_{t}
\end{aligned}
$$


where $\alpha_{0}$ is intercept, $\beta_{i}$ is the coefficient of the lag of the dependent variable with $i=$ $1,2, \ldots, n, t=1,2, \ldots, T, \delta_{i}$ is the coefficient of the short-run variables, with where $i=$ $1,2,3, \ldots, 11$ and $\lambda$ is the feedback effect, adjustment effect or error correction coefficient.

\section{Estimations and Results}

The objective of employing VECM is to have a detailed impact of $O P$ on $E C$ along with interactions of $O P$. After determining the number of cointegrations, estimate the VECM. The Aikake Information Criterion (AIC) score of $\left(146.2^{*}\right)$ indicates that the optimum lag should be three for the VECM model. Therefore, the model opts for three lags in Table 1.

Table 1: VAR Lag Order Selection Criteria

\begin{tabular}{|c|c|c|c|c|c|c|}
\hline Lag & LogL & LR & FPE & AIC & SC & HQ \\
\hline 1 & -2043.41 & NA & $5.30 \mathrm{e}+32$ & 98.01 & 100.64 & 98.98 \\
\hline 2 & -1885.87 & 197.83 & $8.92 \mathrm{e}+30$ & 93.66 & 98.91 & 95.60 \\
\hline 3 & -1760.95 & $110.39^{*}$ & $1.23 \mathrm{e}+30^{*}$ & $90.83^{*}$ & $98.69^{*}$ & $93.73^{*}$ \\
\hline
\end{tabular}

* indicates lag order selected by the criterion

The trace test indicates at least six cointegrating equations have a p-value less than $\alpha=$ 0.05 , implying that we can reject the null hypothesis of no cointegration. The trace test shows evidence for superior performance in cases in which the process has two or more than two cointegrating interactions than the amount enumerated under the null hypothesis. Lütkepohl et al. (2001) concluded by advising the researcher to execute both tests simultaneously or even to apply the trace test exclusively. On the other hand, the max-eigenvalue test also shows that at least six cointegrating equation have a p-value less than $\alpha=0.05$ implying the occurrence of long-run cointegration amongst model while rejecting the null hypothesis of 'no cointegration'. Thus suffice the requirement of the long-run relationship shown in Table 2.

Table 2: Unrestricted Cointegration Rank Test (Trace)

\begin{tabular}{|l|c|c|c|c|c|c|}
\hline $\begin{array}{l}\text { Hypothesized } \\
\text { No. of CE(s) }\end{array}$ & Eigenvalue & $\begin{array}{l}\text { Trace } \\
\text { Statistic }\end{array}$ & $\begin{array}{l}\text { Critical } \\
\text { Value }\end{array}$ & $\begin{array}{l}\text { Max-Eigen } \\
\text { Statistic }\end{array}$ & $\begin{array}{l}\text { Critical } \\
\text { Value }\end{array}$ & Prob. \\
\hline None & 1.00 & 697.2 & 159.5 & 243.2 & 52.3 & 0.00 \\
\hline At most $1 *$ & 0.97 & 453.9 & 125.6 & 154.3 & 46.2 & 0.00 \\
\hline At most 2 $*$ & 0.94 & 299.5 & 95.7 & 121.3 & 40.0 & 0.00 \\
\hline At most 3 $*$ & 0.81 & 178.2 & 69.8 & 69.8 & 33.8 & 0.00 \\
\hline At most 4 & 0.74 & 108.3 & 47.8 & 56.0 & 27.5 & 0.00 \\
\hline At most 5 & 0.64 & 52.2 & 29.8 & 43.2 & 21.1 & 0.00 \\
\hline At most 6 & 0.19 & 9.0 & 15.4 & 9.0 & 14.2 & 0.28 \\
\hline At most 7 & 0.00 & 0.02 & 3.8 & 0.0 & 3.8 & 0.90 \\
\hline
\end{tabular}

\section{A. Long Run Impact of Oil Prices on Energy Crisis.}

In dynamic modelling of time series, the movement of variables at any time is subject to previous period's gaps after long-run, specifically, it shows long-run connection among 
series. The coefficient of $O P$ is positive (0.9) and significant as $\tau$-statistics is greater than (1.96), which thus implies that in long-run $O P$ deteriorates the supply-demand of energy balance. Thus the results imply that $O P$ is a significant and persistent contributor of $E C$ in the country in the long-run. These results are in accordance and aligned by the oil price theory. The total effect of $O P$ on $E C$ is $\frac{\partial E C}{\partial O P}=0.91-0.05 * C D+1.28 * T D L-1.3 * E M=0.896$. The actual amount of effect is determining by the magnitude of interaction term $C D^{*} O P, T D L^{*} O P$ and $E M^{*} O P$ show the indirect effect of $O P$ on $E C$ and is significant, positive in long-run. This implies that the situation of $E C$ enhances every time the international $O P$ hike, as it increases the burden of import bills and supply chain due to which the liability in the form of $C D$ increases significantly, second, it puts downward pressure on energy production. Third, the losses $T D L$ deteriorates the energy supply-demand balance. Finally, the irrationality of EM pushes the domestic wealth outflow upward thus significantly threatens the energy security and $E C$ in long-run complete statistics/results are in Table 3.

Table 3: Vector Error Correction Estimates

\begin{tabular}{|l|l|l|l|}
\hline & CointEq1 & Standard errors & t-statistics \\
\hline EC(-1) & 1 & & \\
\hline OP(-1) & 0.906775 & -0.26109 & {$[3.47303]$} \\
\hline PIS(-1) & -56.6468 & -1.37811 & {$[-41.1046]$} \\
\hline POP(-1) & $1.04 \mathrm{E}-05$ & $-4.80 \mathrm{E}-07$ & {$[21.7190]$} \\
\hline GDP(-1) & $-6.49 \mathrm{E}-09$ & $-2.90 \mathrm{E}-10$ & {$[-22.5134]$} \\
\hline CD*OP(-1) & 0.054219 & -0.00159 & {$[34.0443]$} \\
\hline TDL*OP(-1) & 1.272777 & -0.04285 & {$[29.7063]$} \\
\hline PIS*OP(-1) & 1.54474 & -0.04077 & {$[37.8873]$} \\
\hline EM*OP(-1) & -1.340357 & -0.04709 & {$[-28.4618]$} \\
\hline INF(-1) & 0.519643 & -0.51462 & {$[1.00977]$} \\
\hline C & -427.0128 & & \\
\hline
\end{tabular}

However, the situation has been pretty gruesome when it comes to political stability, as shown by the results that the political crisis is a significant contributor to the prevailing $E C$ in the country. The results are not only in synergy with the proposed theory of Lipset (1959) but also endorse and proves the underlined hypothesis of this study. The impact of the population is positive and significant, which implies that increasing $P O P$ has been one significant pressure on energy resource utilization and distribution. Due to which the supplydemand gap increased and exploded. Thus results support the underlined theory and hypothesis of this research that increasing demand is population-driven which is a weighty sponsor to $E C$ in the state. Whereas, GDP shows a negative and significant impact on $E C$ in the long run. This means that economic growth and development is the single most important counter factor to 
tackle the increasing pressure of supply-demand imbalance in the country. Thus the dwindling economy and economic situation have been a significant factor in bringing the society to the verge of energy collapse, especially in the last two decades. Thus the results are a perfect reflection of reality and theory of this study.

Table 4 shows least-square coefficients extracted from the VECM. In order to have the confirmation of the long-run presence and significance between $O P$ and $E C$, the coefficient of cointegrating equation i.e. $\mathrm{C}(1)$ herein representing long-run coefficient should be negative, less than one and its $p$-value should be less $\alpha=0.05$. As the results exhibit that the $\mathrm{C}(1)$ is 0.41 , having $p$-value 0.01 thus rejecting the null hypothesis of no long-run relationship. Moreover, it imposes that the model would converge to steady-state with the speed of 41 percent annually in case of any shock. Furthermore, the Wald test is employed to test the hypothesis of long-run relationship's significance. Wald test is used to know the long -run relationship's significance and presence. As both $\tau$-statistics and $F$-statistics are less than five percent, thus we can reject the null hypothesis of no long-run relationship, and thus prevails the long run relationship. Hence, in conclusion, there exists a long-run relationship from defined explanatory variables and the dependent variable.

Table 4: Wald Test for Long Run Relationship

\begin{tabular}{|l|c|c|c|}
\hline Test Statistic & Value & df & Probability \\
\hline$t$-statistic & -3.03 & 21.00 & 0.01 \\
\hline$F$-statistic & 9.20 & $(1,21)$ & 0.01 \\
\hline Chi-square & 9.20 & 1.00 & 0.00 \\
\hline Normalized Restriction (=0) & & Value & Std. Err. \\
\hline $\mathrm{C}(1)$ & & -0.41 & 0.14 \\
\hline
\end{tabular}

*Restrictions are linear in coefficients.

\section{B. Short Run Impact of Oil Prices on Energy Crisis.}

Estimates of the VECM entail in Table 5, shows the model with $E C$ as a dependent is selected herein for investigating the presence and significance of relationship in the short-run. The magnitude of the coefficient of the $E C T_{t-l}$ is a signal of the speed of the adjustment towards the equilibrium. The $E C T_{t-1}$ is significant having a negative sign, therefore, suggests that in case of a deviation from the previous period the model has 41 percent tendency of readjustment and to converge back to steady-state, ceteris paribus. It shows a fair and significant adjustment rate towards steady-state. It also means that one percent change in previous $E C$ is associated with negative 41 percent change in current $E C$, that is in short-run previous year crisis might reduce current year situation. A unit change in $O P$ is associated with a 54 percent change in $E C$, which implies that the immediate impact of $O P$ on $E C$ positive and significant. This implies, in the 
short run under VECM there is a strong effect of oil price dynamics on $E C$. Whereas the coefficient of PIS is negative, showing the theoretically appropriate relationship with $E C$, but the relationship is non-significant in the short run. Therefore, a weak but positive significant impact of the population can be inferred from the results, which shows the more or less same impact on the crisis in the immediate and far short run, that is population growth worsens the situation of $E C$. Similarly, the coefficient of GDP is weak and significant at the second lag, which implies that economic growth needs ample time to have any impact on the $E C$.

Table 5: VECM Short Run Results

\begin{tabular}{|c|c|c|c|}
\hline Error Correction & D(EC) & Standard Error & t-Statistics \\
\hline CointEq1 & -0.41 & -0.14 & {$[-3.03369]$} \\
\hline $\mathrm{D}(\mathrm{EC}(-1))$ & -0.41 & -0.18 & {$[-2.24203]$} \\
\hline $\mathrm{D}(\mathrm{EC}(-2))$ & -0.07 & -0.17 & {$[-0.42141]$} \\
\hline $\mathrm{D}(\mathrm{OP}(-1))$ & 0.54 & 0.65 & {$[-4.67443]$} \\
\hline $\mathrm{D}(\mathrm{OP}(-2))$ & 0.70 & -1.57 & {$[0.44337]$} \\
\hline $\mathrm{D}(\mathrm{PIS}(-1))$ & -11.14 & -8.25 & {$[-1.35162]$} \\
\hline $\mathrm{D}(\mathrm{PIS}(-2))$ & -11.56 & -7.33 & {$[-1.57695]$} \\
\hline $\mathrm{D}(\mathrm{POP}(-1))$ & 0.00 & 0.00 & {$[-2.79252]$} \\
\hline $\mathrm{D}(\mathrm{POP}(-2))$ & 0.00 & 0.00 & {$[2.76280]$} \\
\hline $\mathrm{D}(\mathrm{GDP}(-1))$ & 0.00 & 0.00 & {$[-1.83912]$} \\
\hline $\mathrm{D}(\mathrm{GDP}(-2))$ & 0.00 & 0.00 & [ 2.97576] \\
\hline $\mathrm{D}(\mathrm{CD} * \mathrm{OP}(-1))$ & 0.01 & -0.01 & [ 1.52450$]$ \\
\hline $\mathrm{D}(\mathrm{PIS} * \mathrm{OP}(-1))$ & 0.13 & -0.25 & [ 0.53265$]$ \\
\hline $\mathrm{D}(\mathrm{PIS} * \mathrm{OP}(-2))$ & 0.28 & -0.22 & [ 1.29031$]$ \\
\hline $\mathrm{D}(\mathrm{EM} * \mathrm{OP}(-1))$ & -0.18 & -0.16 & {$[-1.10323]$} \\
\hline $\mathrm{D}(\mathrm{EM} * \mathrm{OP}(-2))$ & 0.20 & -0.16 & [ 1.24956$]$ \\
\hline $\mathrm{D}(\mathrm{INF}(-1))$ & -3.30 & -2.55 & {$[-1.29478]$} \\
\hline $\mathrm{D}(\mathrm{INF}(-2))$ & 1.79 & -3.01 & [ 0.59476$]$ \\
\hline $\mathrm{C}$ & 373.46 & -161.19 & [ 2.31693] \\
\hline R-squared & 0.66 & Log-likelihood & -237.10 \\
\hline Adj. R-squared & 0.33 & Akaike AIC & 12.05 \\
\hline Sum sq. resides & 155018.20 & Schwarz SC & 12.95 \\
\hline S.E. equation & 85.92 & Mean dependent & 13.18 \\
\hline F-statistic & 1.98 & S.D. dependent & 104.86 \\
\hline
\end{tabular}

\section{Diagnostic Checking.}

The autoregressive polynomial is a diagnostic that investigated the stability of VECM. Inverse roots of polynomials are within the stability circle, thus implies that the model has no stability issue. Hence the model can be relied upon for analysis. If the projected ARMA procedure is (covariance) stationary, then all AR roots should lie inside the unit circle. Whereas, if the assessed ARMA procedure is invertible, then all MA roots should lie inside the unit circle. Figure 1 entail displays all roots in order of decreasing (square root of the sum of squares of the real and imaginary parts). As the $p$-value of LM statistics is 0.36 in Table 6 which 
is greater than five percent, thus we are unable to reject the null hypothesis of no serial correlation. Thus the VECM model tested herein has no issue of serial correlation and can be relied upon its outcomes.

\section{Table 6: VEC Residual Serial Correlation LM Tests}

\begin{tabular}{|l|c|c|}
\hline Lags & LM-Stat & Prob \\
\hline 1 & 104.65 & 0.36 \\
\hline Probs from chi-square with 100 df. & & \\
\hline
\end{tabular}

A graphic depiction of the Cumulative Sum (CUSUM) in Figure 2 established and descent within the satisfactory region with Akaike graph that reinforced our maximum lag selection criterion.

\section{Figure 1: Inverse Roots of AR Characteristic Polynomial}

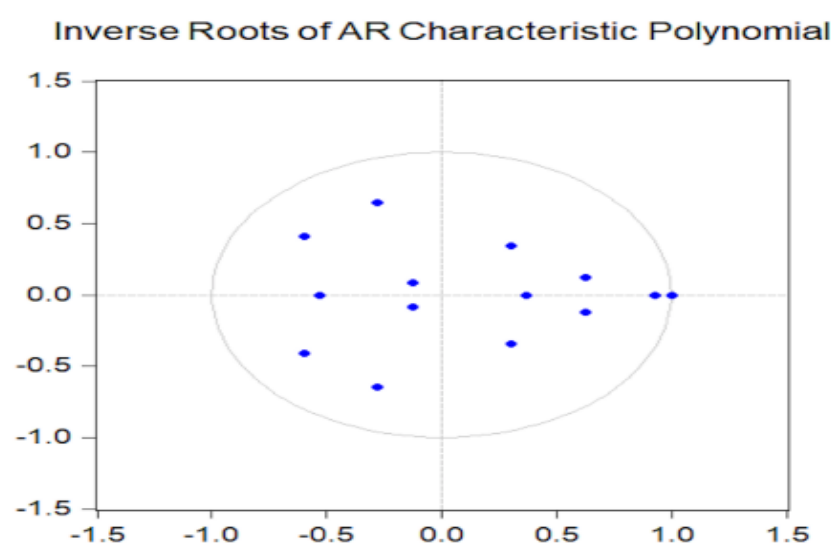

Figure 2: CUSUM Test

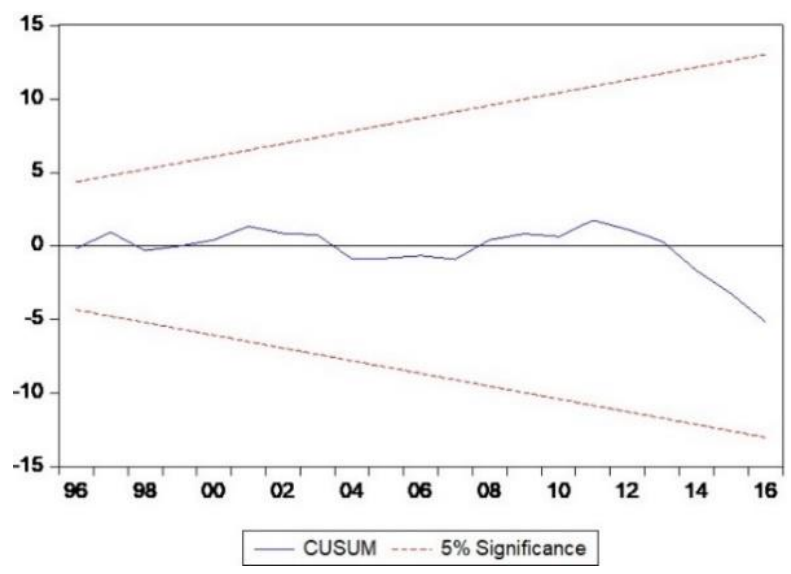

\section{Conclusion \& Policy Recommendations.}

The primary objective of conducting VECM here remained to test the character in supply oil price volatilities on supply-demand dynamics of energy in the country. As Pakistan 
is heavily reliant on imported oil, therefore, the international oil price dynamics show a significant role in explaining persistent and ongoing energy crisis. The results affirmed the positive significant influence of oil prices upon the energy crisis, in the long run, is greater compared to the short run. Wherein, the total indirect effect of oil prices is also positive and significant. Therefore, institutional reforms and restructuring of the energy mix with enhancing the renewable energy sources and indigenous sources are mandatory conditions for mitigating the impact of oil prices. Similarly, political instability signifying the negative long-run impact on the energy crisis. Therefore, the sustainability of institutional reforms and restructuring depends upon the political stability, thus legislation on energy mix is solicited to remove the adhocism in decision making so that the dependency on external markets for energy supplies could be reduced, along with the population growth and energy demand. Therefore, policy initiatives on reducing the imported energy, enhancing the alternative energy supplies on war footings are inevitable to put a bar on increasing damages of oil price volatilities and to reduce the crisis.

\section{References}

Abeyasinghe, R. (2004). Democracy, political stability, and developing country growth: Theory and evidence. Illinois Wesleyan University, Economics. Andrew W. Mellon Center for Curricular and Faculty Development.

Ahmed, A. (2014). Energy smart buildings: Potential for conservation and efficiency of energy: The Pakistan Development Review, 371-380.

Alahdad, Z. (2012). Pakistan's energy sector from crisis to crisis, breaking the chain. Islamabad: Pakistan Institute of Development Economics.

Ali, M., Iqbal, M. J., \& Sharif, M. (2013). Relationship between extreme temperature and electricity demand in Pakistan. International Journal of Energy and Environmental Engineering, 4(1), 36.

Ali, S. (2014). Inflation, Income inequality and economic growth in Pakistan: A cointegration analysis. International Journal of Economic Practices and Theories, 4(1), 33-42

Awan, A. B., \& Khan, Z. A. (2014). Recent progress in renewable energy-remedy of energy crisis in Pakistan. Renewable and Sustainable Energy Reviews, 33, 236-253.

Azam, M., Khan, A. Q., Zafeiriou, E., \& Arabatzis, G. (2016). Socio-economic determinants of energy consumption: An empirical survey for Greece. Renewable and Sustainable Energy Reviews, 57, 1556-1567.

Belk, R., Painter, J., \& Semenik, R. (1981). Preferred solutions to the energy crisis as a function of causal attributions. Journal of Consumer Research, 8(3), 306-312.

Bhatti, A. G., Bhatti, A. R., Chaudhary, I. A., \& Javed, M. N. (2012). Energy crisis in Pakistan, adaptation and mitigation measures. Journal of Faculty of Engineering \& Technology, 19(1), 67-82.

Bhatti, et al., (2015). Electric power transmission and distribution losses overview and minimization in Pakistan. International Journal of Scientific \& Engineering Research, 6(4), 1108-1112. 
Chapman, D., Tyrrell, T., \& Mount, T. (1972). Electricity demand growth and the energy crisis. Science, 178(4062), 703-708.

Congleton, R. D. (2005). The political economy of crisis management: Surprise, urgency, and mistakes in political decision making. Centre for Study of Public Choice George Mason University Fairfax VA 22030 and Faculty of Philosophy University of Bayreuth Bayreuth, Germany. Elsevier.

Hasan, S. A., Subhani, M. I., \& Osman, M. (2012). The energy short fall and its after effects (a case study for Karachi city in context to Karachi electric supply corporation).

Hogan, W. W. (2002). Electricity market restructuring: reforms of reforms. Journal of Regulatory Economics, 21(1), 103-132.

Hussain, J. (2018). Energy sector development: Optimum resource challenges and opportunities. Parliamentary Research Digest, 4(11). 13-22.

K. S., Pesaran, M. H., \& Shin, Y. (2003). Testing for unit roots in heterogeneous panels. Journal of Econometrics, 115(1), 53-74.

Khaliq, A., Ikram, A., \& Salman, M. (2015). Quaid-e-Azam solar power park: Prospects and challenges. In Power Generation System and Renewable Energy Technologies, 1, 1-6

Kessides, I. N. (2013). Chaos in power: Pakistan's electricity crisis. Energy Policy (55), 271285.

Kugelman, M. (2013). Pakistan's energy crisis. National Bureau of Asian Research: Washington, $D C$.

Lipset, S. M. (1960). The political man: The social bases of politics. NewYork, DC, USA: Doubleday \& Company, INC.

Lipset, S. M. (1959). Some social requisites of democracy: Economic development and political legitimacy. The American Political Science Review, 53(1), 69-105.

Mahmood, R., \& Shah, A. (2017). Deprivation counts: An assessment of energy poverty in Pakistan. The Lahore Journal of Economics, 22(1), 109-132

Malik, A. (2012). Power crisis in Pakistan: a crisis in governance? PIDE Monograph Series.

Masood, M. T., \& Shah, F. (2012). Dilemma of third world countries-problems facing Pakistan energy crisis a case-in-point. International Journal of Business and Management, 7(5), 231-245.

Milina, V. (2013). Energy security: A paradigm shift. Connections, 12(4), 75-98

Mirjat, N. H., Uqaili, M. A., Harijan, K., Valasai, G. D., Shaikh, F., \& Waris, M. (2017). A review of energy and power planning and policies of Pakistan. Renewable and Sustainable Energy Reviews, 79, 110-127.

Mufti, G. M., Jamil, M., Nawaz, M., Rehman, M., \& Hassan, S. Z. (2016). Evaluating the issues and challenges in context of the energy crisis of Pakistan. Indian Journal of Science and Technology, 9(36), 1-7.

Narayan, P. K. (2005). The saving and investment nexus for China: Evidence from cointegration tests. Applied Economics, 37(17), 1979-1990.

Nelson, C. R., \& Plosser, C. R. (1982). Trends and random walks in macroeconomic time series: Some evidence and implications. Journal of Monetary Economics, 10(2), 139-162.

Pesaran, M. H., Shin, Y., \& Smith, R. J. (2001). Bounds testing approaches to the analysis of level relationships. Journal of Applied Econometrics, 16(3), 289-326.

Pesaran, M. H., Shin, Y., \& Smith, R. P. (1999). Pooled mean group estimation of dynamic heterogeneous panels. Journal of the American Statistical Association, 94(446), 621634.

Pesaran MH, Shin Y, Smith RJ (2001) Bounds testing approaches to the analysis of level relationship. Applied Econometrics 16:289-326 
Qasim, M., \& Kotani, K. (2013). Causes of energy shortage in Pakistan: An empirical evidence. Economics \& Management Series. 1, 1-25.

Rafique, M. M., \& Rehman, S. (2017). National energy scenario of Pakistan, current status, future alternatives, and institutional infrastructure: An overview. Renewable and Sustainable Energy Reviews, (69), 156-167.

Rosa, E. A., Machlis, G. E., \& Keating, K. M. (1988). Energy and society. Annual Review of Sociology, 14(1), 149-172.

Sakrani, H., Butt, T. T., Hassan, M., Hameed, S., \& Amin, I. (2012). Implementation of load shedding apparatus for energy management in Pakistan. In International Multi Topic Conference. (421-431). Springer, Berlin, Heidelberg.

Shakir, M., Haq, I. U., Khan, M. A., Malik, S. A., \& Khan, S. A. (2014). Alternate energy resources for Pakistan: Sustainable solutions for fulfilling energy requirements. World Applied Sciences Journal, 31(5), 718-723.

Sheikh, M. A. (2010). Energy and renewable energy scenario of Pakistan. Renewable and Sustainable Energy Reviews, 14(1), 354-363.

Siddiqui, R. (2004). Energy and economic growth in Pakistan. The Pakistan Development Review, 43(2), 175-200.

Stern, D. I. (1993). Energy and economic growth in the USA: A multivariate approach. Energy Economics, 15(2), 137-150.

Stern, D. I., \& Cleveland, C. J. (2004). Energy and economic growth. Encyclopedia of Energy, 2, 35-51.

Tabassam, A. H., Hashmi, S. H., \& Rehman, F. (2016). Nexus between political instability and economic growth in Pakistan. Procedia: Social and Behavioral Sciences, 230, 225-234.

Taneez, M., Saleem, M., \& Ahmad, S. S. (2013) Quantifying the present challenges and future perspectives of energy crisis in Pakistan. International Journal of Emerging Trends in Engineering and Development, 3(5), 108-114.

Ullah, K. (2013). Electricity Infrastructure in Pakistan: An overview. International Journal of Energy, Information and Communications, 4(3), 11-26.

Ullah, K., Arentsen, M. J., \& Lovett, J. C. (2016). Institutional determinants of power sector reform in Pakistan. Energy Policy, 102, 332-339.

Uqaili, M. A., \& Harijan, K. (2011). Energy, environment and sustainable development. Springer Science \& Business Media. New York.

Valasai, G. D., Uqaili, M. A., Memon, H. R., Samoo, S. R., Mirjat, N. H., \& Harijan, K. (2017). Overcoming electricity crisis in Pakistan: A review of sustainable electricity options. Renewable and Sustainable Energy Reviews, 72, 734-745.

Zaidi, S. A. (2015). Issues in Pakistan's economy, 3rd ed. Oxford University Press. Print

Zameer, H., \& Wang, Y. (2017). Energy production system optimization: evidence from Pakistan. Renewable and Sustainable Energy Reviews, 82, 886-893.

Zuberi, M. J. S., \& Ali, S. F. (2015). Greenhouse effect reduction by recovering energy from waste landfills in Pakistan. Renewable and Sustainable Energy Reviews, 44, 117-131. 